\title{
INTEGRATED ASSESSMENT MECHANISM OF THE SUSTAINABLE DEVELOPMENT POTENTIAL OF UKRAINIAN COMPANIES
}

\author{
Olha Hrybinenko \\ Department of Economic Enterprise, State Institution of Higher Education "Dnipro University \\ of Technology", 19 D. Yavorniskogo ave., Dnipro, Ukraine, 49005 \\ E-mail:Hrybinenko.o.m.@nmu.one
}

\begin{abstract}
This research paper aims at providing a scientific substantiation of the mechanism of integrated evaluation of the potential of sustainable development of Ukrainian companies in the modern conditions. The research methodology is based on a systematic approach and generalization of factors that influence the implementation of the potential of companies sustainable development. It is shown that a structured, integrated evaluation of the potential of sustainable development within a certain system, algorithm of actions embodied in the form of evaluation mechanism, contributes greatly to the success of the practical application of the management tools for the companies's sustainable development, enabling the adequate response to changeability of market environment and create the preconditions for long-term development.
\end{abstract}

Keywords: sustainable development, company, potential, evaluation mechanism, integrated evaluation, Ukraine.

JEL Classification: O12, O20.

\section{Introduction}

Modern business conditions of Ukrainian companies determine the need for the formation of sustainable competitive advantages and the dynamism of development as a basis for ensuring the long-term competitiveness of these companies. At the same time, the conceptual basis of the development of the modern economy is the paradigm of sustainable socio-ecologo-economic development, which involves the orientation to a harmonious combination of efforts towards the achievement of the goals of economic, social and ecological nature (Report of the United Nations Conference on Environment and Development, 1992; Sustainability and performance assessment..., 2012; WRI, 2017).

The paradigm has become widely spread as a principological basis for the formation of a new global economy and developed economies, i.e. at the global and macro levels. At the same time, micro level is the foundation and the environment for implementing solutions which are significant for local and global economies, that urges the importance of promoting the ideas and principles of sustainable development at the company level. However, to date, there has not been a clear methodological approach to the consideration of structural changes in the transitional economy, features and mechanisms of structural transformations in the economy of industries and companies on the basis of sustainable development. At the same time, modern economic processes determine the need for a comprehensive study of structural changes in the economy of companies, taking into account the peculiarities of development for further identification of general and specific trends in the development of the state's economy.

Traditional methods of managing industrial companies of Ukraine are not sufficiently effective in a fast-changing highly competitive business environment. Sustainable development of companies involves the coordination of shortterm goals and interests of different groups and individuals as part of the company with long-term strategic objectives stipulated by the requirements of its internal development. In this regard, sustainable development management is an important condition for the efficient activity of domestic companies. One of the most urgent issues of economic studies is the search for ways to ensure sustainable management process development of domestic companies adequate to new economic conditions.

The study and generalization of the scientific papers of economists showed that the aspects related to the specifics of functioning of Ukrainian companies in the conditions of globalization of the economy and strengthening of competition in 
the process of European integration due to signing of the EU Association Agreement (Problems of management and economy of companies in the modern conditions, 2017) are still insufficiently studied though they are being actively developed. A similar, globalizational specifics is a characteristic feature for other transitional economies. In general, it differs in the vector of orientation of integration transformations at the level of the markets.

That is why Ukraine, as a country with a dynamic change in the environment of functioning of companies, which requires a quick and effective response to these changes, the effectiveness of which is important in the long term not only for economic but also for social development and preservation of ecology, has been chosen as a country to be considered in this paper in the process of formation of research findings, being important for the theory and practice of this country and other countries.

This research paper aims at scientific substantiation of the mechanism of integrated evaluation of the sustainable development potential of Ukrainian companies in the modern conditions.

In the process of achieving this goal the following tasks have been fulfilled: coverage of the problems of evaluation of the companies' sustainable socio-ecologo-economic development potential; characteristics of the structure and stages of implementation of the mechanism of evaluation of sustainable development potential; determination of the role of this mechanism in the management process of Ukrainian companies' sustainable development.

\section{Conceptual foundation of sustainable development}

The concept of sustainable development was formed as an understanding of the new socio-economic processes of "socialization" and "ecologization" of the conditions of functioning of the modern economy, as an attempt to solve the contradictions "economy and personality", "economy and future of new generations", "economy and social responsibility", "economy and environment" by applying the synthetic category of socioecologo-economic development (Bastina, 2017; Report of the United Nations Conference on Environment and Development, 1992).

The studies (UNEP, 2012; Barua, Fransen, \& Wood, 2014) deal with sustainable development issues; these papers cover the problems and trends of formation of the sustainable development concept as a key paradigm and a trajectory of socioeconomic progress, while they do not present any integrated approach to the management and evaluation of the sustainable development potential at the micro-level, oriented to achieving competitiveness in the domestic and foreign markets.

The papers where the comparative analysis of solving specific problems of sustainable development in developing countries (Kamel \& Dahl, 2004; Thorne \& Raubenheimer, 2001; Report of the International Ministerial Conference..., 2003) is carried out are worth mentioning. These studies are important for understanding the specifics of development activities at the macro and micro levels in the countries of the former USSR, along with papers dealing with the reflection of successful experiences in Eastern Europe and developing countries (Imas, Morra, \& Ray, 2009; Nilsson, 2016).

At the same time, these works reflect ways to solve specific development problems without the context of ensuring long-term balanced socioecologo-economic development. There are ongoing discussions about the role of the state in ensuring the conditions for sustainable development of companies (Bastow, 2013; Artemov, Brykin, \& Shumaev, 2008; OECD, 2012), the reasonableness of government regulation measures and the formation of balance of government intervention in the market processes.

Consideration of this problem in the context of satisfying primarily the long-term interests of society (Hudon \& Huybrechts, 2017), which was formed at the global level, urged at the macro level and has become more and more common at the company level in recent decades, is interesting while revealing the direction of development of scientific thought on sustainable development. An example of this is that the development of scholars is being implemented, for example, within the framework of the models of sustainable development management system (Wry \& York, 2017; Corde, 2017), and is based on organically combined system and integrated approaches.

On the basis of developments of modern scholars reflecting the theory of social enterpreneurship (Munro \& Belanger, 2017; Picciotti, 2017; Corde, 2017), a wide range of issues of ensuring companies' sustainable development and the formation of national economic priorities are considered, taking into account the potential of this development. 
At the same time, the problem of this theory, as well as other ones, for example, the concepts giving priority to the environmental factor (ÜrgeVorsatz, Tirado, Dubash, \& Lecocq, 2014) or the economic one (Hudon \& Huybrechts, 2017) is either their one-sidedness, the rejection of the importance of other factors and the need for their integrated consideration, or focusing on problemsolving at a certain level, mainly on the global level, and more rarely on the macro level, despite the fact that the economic activity itself is carried out at the company level and its role in the effectiveness of the development of society is extremely important.

An important problem in this context is the problem of finding a way to assess the prerequisites and identify development priorities. In particular, researchers (Carpenter \& Moss, 2014) still consider an increase in profits to be such a priority. At the same time, this cannot be accepted in the modern conditions, as the experience of developed countries shows that the solution of development problems requires a comprehensive formation of reference points that can include, in addition to profits, increasing the scale of presence in the markets, solving global problems of supply of food, increasing competitiveness, ensuring social and environmental prerequisites for the development (Srebotnjak, Polzin, Giljum, Herbert, \& Lutter, 2010; OECD, 2008).

\section{Methods and materials}

The theoretical basis of the research paper was the key provisions of modern economic theory and modern concepts of sustainable socioecologo-economic development, strategic management covered in the scientific papers of domestic and foreign scholars.

The research methodology is based on a systematic approach and generalization of factors that influence the implementation of companies' sustainable development potential.

To achieve the objective of the reserch paper, a system of general scientific and special methods of research of processes and phenomena in their interrelation and development was used, namely: methods of theoretical analysis and synthesis (for describing the essence of concepts); methods of theoretical modeling (for choosing an optimal interaction structure within the evaluation mechanism); methods of systematization, grouping and logical generalization (for systematization of information, drawing conclusions and scientific proposals of the reserch paper); methods of structural and logical analysis - for presentation of the mechanism of integrated evaluation and features of socio-ecologo-economic development.

Sustainable development at the company's level is represented as a complex of elements and properties, with their interaction forming a new integrity of the modern world. The methodological means which logically continue the system and structural approach is a synergistic approach and the principle of co-evolution. The synergetic approach is based on the theory of self-organization and involves a comprehensive accounting for the links between different levels and forms between elements of the system, with their development strengthening its integrity and efficiency, the possibility of its diverse development, and also makes the emergence of a new quality possible. The use of the principle of co-evolution in this study can be particularized in the context of the unity and interaction of the natural and social in the human's essence.

\section{Formation of the mechanism of integrated evaluation of the sustainable development potential of Ukrainian companies}

\subsection{Objectives and principles of integrated evaluation of the sustainable development potential of Ukrainian companies}

The conditions that characterize the current state of sustainable development of Ukrainian comapnies, as it was determined according to the results of the analysis of the sources (Problems of management and economy of companies in the modern conditions, 2017; Problems of sustainable development of the economy in the conditions of strengthening globalization processes, 2017; Vladimir, 2017) and the own observations of the author of this research paper, are as follows: for the formation of tools and, especially, strategies for sustainable development of domestic companies, systematized information on their activities and the impact of the external market environment is not sufficient; tools of sustainable development of domestic companies are formed in the conditions of insufficiency of material and financial resources, which are necessary for stirring up of such development; sustainable development of companies in Ukraine manifests itself as an unformalized process, which depends on many formal and informal factors; there are no standards which can be the basis for obtaining a conclusion on the 
influence of key factors on the companies' sustainable development; the tasks to be solved with the help of the mechanisms of sustainable development of Ukrainian comapnies are not set or expressed in concepts that are not related to sustainable development; the tools for the sustainable development of Ukrainian companiesare being introduced without sufficient prior scientific and research substantiation.

It is obvious that there is a need to provide a full evaluation of the companies' sustainable development potential as the initial stage of management and the basis for justifying the tools for managing companies' sustainable development. As goals of the integrated evaluation of the potential of sustainable socio-ecologo-economic development of Ukrainian companies, according to the author, which is based on the analysis of refrences (Imas et al., 2009; Nilsson, 2016; Kamel \& Dahl, 2004; Thorne \& Raubenheimer, 2001; Report of the International Ministerial Conference..., 2003), it is reasonable to indicate identification of the preconditions for ensuring: high financial and economic efficiency of functioning of companies, their financial stability; technological conformity of production processes to modern requirements and new opportunities; competitiveness of companies and their products; high management efficiency; high level of personnel qualification and development of its intellectual potential; efficiency of R\&D in these companies; realization of social needs of the company's employees and citizens of the country; provision of safe ecological conditions for the companies' employees; minimization of the devastating impact of consequences of industrial and economic activity on the environment.

The principles of forming a mechanism for integrated evaluation of the sustainable development potential of Ukrainian companies are based on the relevant general evaluation principles: complexity, systemacy, optimality and objectivity.

\subsection{Tools for integrated evaluation of the sustainable development potential of Ukrainian comapnies}

It is reasonable to evaluate the sustainable development potential of companies using a system of criteria and indicators that characterize the possibilities of ensuring sustainable development of the company according to its social, environmental and economic components.

The mechanism for evaluating the Ukrainian companies' sustainable development potential should be focused on identifying opportunities to achieve specific sustainable development goals through characterization of specific factors, which impact on ensuring the companies' sustainable development is based on the use of certain resources or potentials. Such factors include: the company's scope; the company's scale (small, medium, large); stages of the life cycle; conditions of the internal and external environment; mission and determined goals of the company's development; selected development strategies; evaluation methods, etc.

Thus, the model of the mechanism for integrated evaluation of the sustainable development potential of Ukrainian companies envisages taking into account the influence of factors of internal and external environment on the activity of domestic companies and allows not only to evaluate the sustainable development potential of these companies, but also clearly outlines the problem areas and directions of possible increase of the general level of development on the basis of the choice of suggested strategies for the company's development.

\subsection{Structure of the mechanism of integrated evaluation of the sustainable development po- tential of Ukrainian companies}

The mechanism of integrated evaluation of the sustainable development potential of Ukrainian companies is a system of goals, principles, criteria (quantitative analogue of goals) and indicators that allow characterizing quantitative and qualitative factors of influence (elements of the object of management and their relationships, which are influenced to achieve set goals) on the possibility of realizing the companies' sustainable development potential.

This is possible by using a certain methodological base: evaluation methods; resources used for evaluation (material and financial, used in the course of implementation of the chosen method of management, thus ensuring achievement of the set evaluation objectives).

The specified structure is generally typical of socio-economic mechanisms and is based on the sprecification of the methodology of the system approach and its use in practice (Fiore \& Tamborrini, 2014; Kamel \& Dahl, 2004; OECD, 2008).

At the same time, it is important to identify the main elements of the mechanism in view of its purpose and specifics of application, which involves the author's interpretation of the problem of assessing the potential of sustainable development at the company level, which is presented below. 
Scheme of the mechanism of integrated evaluation of the sustainable development potential of Ukrainian companies is presented in Figure 1.
The mechanism for evaluating companies' sustainable development potential is an integral part of the company management system, and is therefore based on general management principles.

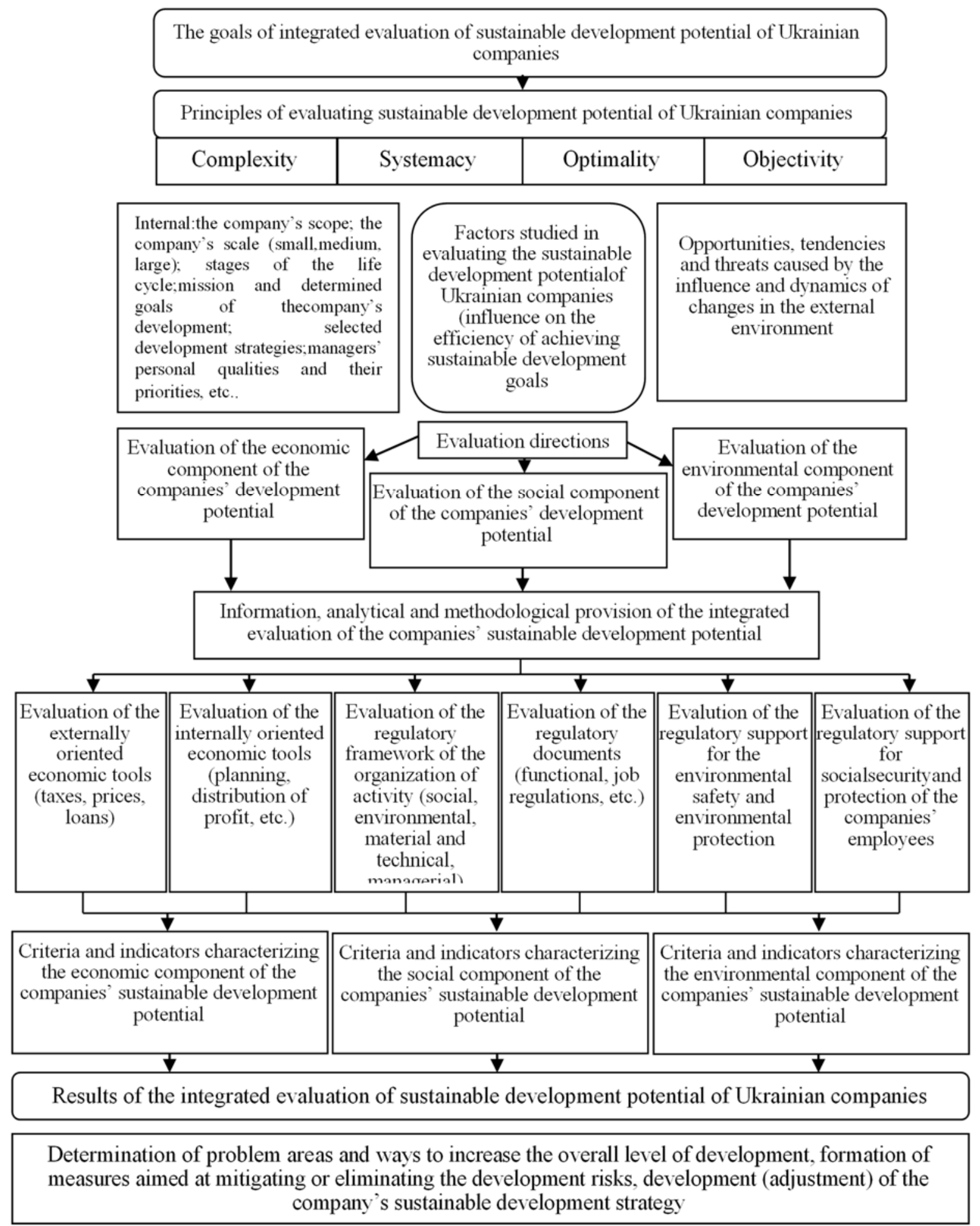

Figure 1. The mechanism of evaluating sustainable development potential of the company's economy 


\subsection{Management based on the mechanism of integrated evaluation of sustainable develop- ment potential of Ukrainian companies}

The methodology of management of companies' sustainable development should be an integrated, coordinated approach to evaluation, regulation and planning of measures.

The presented mechanism of the evaluation should be comprehensive and reflect the company's economic and organizational aspects, being the source element of the management system of company's sustainable development, which is realized through the main stages, with their list composed by the author of this research paper:

1. Identification of problems of the development and ensuring sustainable competitiveness of companies.2. Formation of a system of stimulating sustainable development and increasing competetiveness of comapnies on the basis of existing competitive advantages and results of evaluation of the sustainable development potential and competitiveness of companies.

3. Formation of the companies' sustainable development strategy on the basis of the system of stimulation of their sustainable development and increasing their competitiveness.

4. Monitoring of companies' sustainable development in the process and after implementation of the formed strategy of their sustainable development.

Sustainable development management on the basis of application of the mechanism for evaluating sustainable development potential is shown in Figure 2.

In connection with the scheme, the management of the company's sustainable development on the basis of the results of evaluating its potential, according to the author, should provide for:

1. Evaluation of processes occurring in the companies in terms of their impact on the company's sustainable development.

2. Selection of the strategic direction of the company's sustainable development.

3. Determination of additional tactical priorities of the company's sustainable development.

4. Evaluation of strategic and tactical directions of the development from the standpoint of its sustainability.

5. Development of a plan of measures to improve the mechanisms of companies' sustainable development in accordance with defined strategic and tactical priorities.

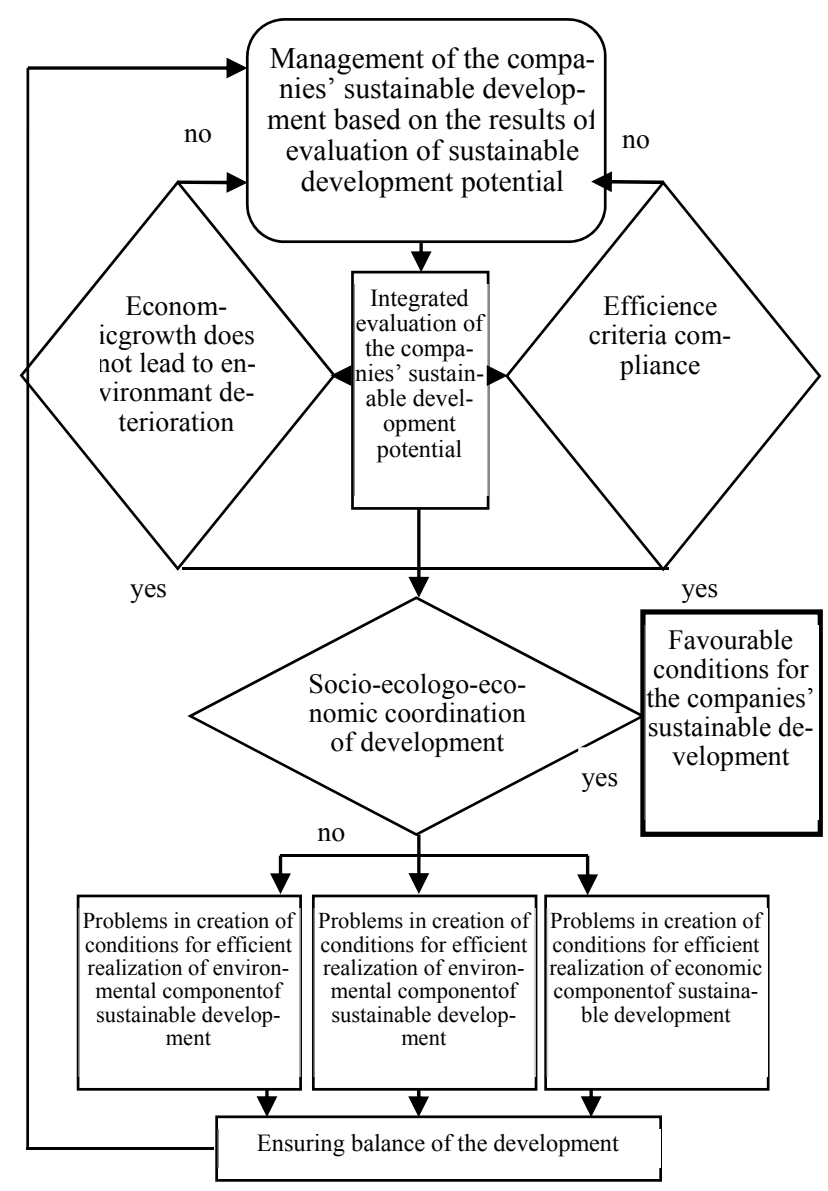

Figure 2. Algorithm of management of the companies' sustainable development based on the results of evaluation of sustainable development potential

Under current conditions, it is important for Ukrainian companies to take advantage of the benefits of social division of labour and to introduce intensive forms of organization of innovative processes (Demirel \& Mazzucato, 2012). The formation of a methodology for managing companies' sustainable development is becoming a determining factor in raising the level of competitiveness of national economy under the current conditions. The conducted researche gives grounds to suggest the following logical scheme on formation of the principles of company's sustainable development: the decomposition of management of the company's sustainable development into the objects of management and management system; introduction of methods based on qualitative and quantitative analysis of the results of sustainable development management with simultaneous limitation of some analyzed indicators; synthesis of managerial influence on the company's activity in the form of the mechanisms of sustainable development. 


\section{Discussion and limitations}

The mechanism of the integrated evaluation of sustainable development potential of Ukrainian companies presented in the research paper in the context of sustainable development largely echoes the principles of the New Growth Theory developed in the 1980's by the American economist Paul Romer (Endogeous Technological Change (Romer, 1999), which implies the endogenous nature of technological development. The foregoing was the reason and methodological basis for implementation of sustainable development in the context of meeting the society's interests, which is implemented, for example, in the model of sustainable economic development system (Fiore \& Tamborrini, 2014), and is based on harmoniously combined systemic and integrated approach. However, unlike similar studies and the ideas of systemic understanding of socially oriented development in the modern conditions formed by other researchers, such as (Fiore \& Tamborrini, 2014; Allen \& Berg, 2014; Ng \& Ho, 2014), this study has attempted to represent interdependence of the basic components of sustainable development at the company level: social, environmental and economic.

The mechanism and suggestions for managing sustainable development presented in the reserch paper are a coherent, interconnected in all its components, set of qualitative and quantitative characteristics that dynamically develop, interact with the environment and have a certain input (clearly fixed by the initial parameters - the objectives of sustainable development) and output (meeting the needs of business and society). And it is the proposed mechanism of evaluation that is an attempt to determine the potential of this interaction, its possible positive effect on the company's development.

This feature necessitates the development of measures to ensure the company's sustainable development potential within the framework of the strategy of sustainable development, continuous diagnostics of its components, control and forecasting, which should be based on an integrated approach to evaluating the companies' sustainable development potential. This will help increase the companies' performance in today's market conditions, identify priorities for implementing the sustainable development potential.

Reliability of the results of this study is ensured by considering the specifics and principles of sustainable development, that allowed to fulfill the scientific task taking into account both economic and socioeconomic needs. Reliability of the results is also confirmed by reasonablenessand proximity of the theoretical substantiation of the research findings obtained to the findings of reputable researchers. In particular, the need to consider sustainable development as the economic basis for building a modern economy has been substantiated taking into account the wellfounded by the leading scholars need to combine the requirement of market rationality (Ürge-Vorsatz et al., 2014) with the right of any individual to participate in the production life, to sufficient material security (Kumar, Americo, \& Billingham, 2016), to his life and the life of his descendants in an environmentally friendly environment (Liu, 2016; Obergassel, Peterson, Mersmann, Schade, Hofbauer, \& Mayr-Hofer, 2017).

The research paper substantiates and systematizes the problems and preconditions for the formation of an effective mechanism for the integrated assessment of the sustainable development potential of Ukrainian companies and, what is especially important, shows the role and place of this mechanism in the management system of sustainable development of these companies. The key value of the research paper is an attempt to evaluate sustainable development potential within a certain system, an algorithm of actions embodied in the form of a structured evaluation mechanism, which, in turn, has a certain influence on the development of tools for managing the sustainable development of Ukrainian companies. In this connection, some limitations in the application of findings of this research paper can be distinguished, namely, the tools for sustainable development management, which are advisable to apply at one or another result of evaluation of the companies' sustainable development potential, may be quite different, therefore the research paper is rather abstract in nature and provides for further detailing of management and evaluation tools. At the same time, this restriction does not reduce the scientific and practical value of this research paper and characterizes the prospects of further development of scientific results obtained by the author.

\section{Conclusions}

It is shown in the research paper that a structured integrated evaluation of sustainable development potential within the framework of a certain system, algorithm of actions embodied in the form of 
anevaluation mechanism, greatly contributes to the success of practical application of the tools of companies' sustainable development management. It is determined that the formation of a mechanism for evaluatingthe company's sustainable development potential contributes to more efficient organization of processes for ensuring reproduction of socio-ecologo-economic aspects of company's development in the modern economic conditions, giving an opportunity to respond adequately to changeability of market environment and create the preconditions for long-term development.

The difference from other studies of the problems of sustainable development, which predetermined the novelty and value of this study, consists in a systematic presentation of ways to evaluate the basic components of sustainable development at the company level (social, environmental, economic) as a set of tools to achieve the goals of sustainable development, through: compliance with certain principles; organization of the necessary information, analytical and methodological support for the integrated evaluation of the companies' sustainable development potential; structuring the evaluation of specific areas (six directions: the indicators in Figure 1); grouping criteria according to the components of social, ecological and economic importance for the disclosure of development potential, which allows drawing separate conclusions about the intensity of certain characteristics of the sustainable development potential; formation of a certain input on the basis of evaluation results, which is important for the characteristics of the possibilities and prerequisites of sustainable development; determination of problem areas and directions for improving the overall development level, the formation of measures aimed at minimizing or eliminating development risks, developing (adjusting) the company's sustainable development strategy.

The management algorithm for companies' sustainable development based on the results of evaluation of the sustainable development potential complements and specifies the possibilities of using the developed evaluation mechanism, reveals the directions of its use in practice.

Thus, the scientific value of this material is to structure and represent the most important (from the standpoint of the conceptual basis of sustainable development) components of the process of evaluation and management of the company's sustainable development potential. This result complements and develops the existing methodological basis of sustainable development management at the company level and may be useful in the future for use in scientific and theoretical research and practice at the company level.

The practical significance of the results obtained in the research paper is that the creation and improvement of the mechanism of integrated evaluation of the sustainable development potential of companies contributes to the formation of directions that would enable to create effective socio-ecologo- economic mechanisms for ensuring the recreation of the company's sustainable development potential, since the hidden unused potential opportunities determine the ability to respond adequately to changeability of the environment and form the priorities for futher development. The indicated opportunities are important for the development of a company in any country, therefore the practical value of this research paper is not limited to Ukraine, which is taken in this case as an example of a country with a dynamic change in the environment of functioning of companies, requiring a quick and effective response to these changes.

The practical implementation of the proposals and conclusions of this research paper should be considered in the context of their importance to stimulate the companies' development, which requires the formation of a certain form of interaction of economic entities within the framework of the paradigm and the principles of sustainable development.

Prospects for further research on the basis and with the use of the scientific findings of this study consist in the analysis, structuring and formalization of sustainable development models and strategies of socio-ecologo-economic-oriented management, in identifying areas for optimization of the company's management system in the modern society.

\section{References}

Allen, D., \& Berg, C. (2014). The sharing economy: how regulation could destroyan economic revolution. Institute of Public Affairs. Retrieved from www.ipa.org.au

Artemov, A., Brykin, A., \& Shumaev, V. (2008). Modernization of public administration in the economy. Ekonomist, 2, 3-14.

Barua, P., Fransen T., \& Wood, D. (2014). Climate policy implementation tracking framework. Working 5 Paper. Washington, DC: World Resources Institute. Retrieved from http://www.wri.org/publication/climate $6 \% 20$ policy-tracking

Bastina, F. (2017). Economic harmonies. Moscow: Eksmo.

Bastow, S. (2013). Governance, performance, and capacity stress: the chronic case of prison crowding. Basingstoke: Palgrave Macmillan.

https://doi.org/10.1057/9781137289162 
Carpenter, D., \& Moss, D. (2014). Preventing regulatory capture: special interest influence and how to limit it. NewYork: Cambridge University Press.

Corde, J. J. (2017). Using cost-benefit analysis and social return on investment to evaluate the impact of social enterprise: promises, implementation, and limitations. Evaluation and Program Planning, 64, 98-104. https://doi.org/10.1016/j.evalprogplan.2016.11.008

Demirel, P., \& Mazzucato, M. (2012). Innovation and firm growth: is R\&D worth it?. Industry and Innovation, 19(1), 45-62. https://doi.org/10.1080/13662716.2012.649057

Fiore, E., \& Tamborrini, P. (2014, June). Open system I bean cultivation for local economical development. Scientific Conference Proceedings (pp. 359-364). Zilina, Slovakia.

Hudon, M., \& Huybrechts, B. (2017). From distant neighbours to bedmates: exploring the synergies between the social economy and sustainable development. Annals of Public and Cooperative Economics, 88, 141-154. https://doi.org/10.1111/apce.12170

Imas, L., Morra, G., \& Ray, R. (2009). The roads to results: designing and conducting effective development evaluations. World Bank Publication. https://doi.org/10.1596/978-0-8213-7891-5

Kamel, S., \& Dahl, C. (2004). The economics of hybri power systems for sustainable desert agriculture in Egypt. Energy (2004, forthcoming). Elsevier.

Kumar, S., Americo, A., \& Billingham, C. (2016). The new social contract: ajust transition. Brussels: Foundation for European Progressive Studies \& Change Partnership. Retrieved from http://www.changepartnership.org/campaigns/

Liu, Q. (2016). Interlinking climate changewith water-energy-food nexusand related ecosystem processes in California case studies. Ecological Processes, 5/1. https://doi.org/10.1186/s13717-016-0058-0

Munro, M., \& Belanger, C. (2017). Analyzing external environment factors affecting social enterprise development. Social Enterprise Journal, 13, 38-52. https://doi.org/10.1108/SEJ-06-2016-0021

$\mathrm{Ng}$, I. C., \& Ho, E. (2014). Creating new markets in the digital economy: valueand worth. NewYork: Cambridge University Press.

Nilsson, M. (2016). Policy: map the interactions between sustainable development goals. Nature, 534. Retrieved from http://www.nature.com/news/policy-map-the-interactions-between-sustainable-development19 goals1.20075

Obergassel, W., Peterson, L., Mersmann, F., Schade, J., Hofbauer, A., \& Mayr-Hofer, M. (2017). Human rights and the clean development mechanism: lessons learned from three case studies. Journal of Human Rights and the Environment, 8(1), 51-71. https://doi.org/10.4337/jhre.2017.01.03

OECD. (2008). Handbook on constructing composite indicators: methodology and userguide. OECD \& European Commission Joint Research Centre.
OECD. (2012). Background Report for the OECD Strategyon Development, C(2012)61/REV1. Paris: OECD.

Picciotti, A. (2017). Toward sustainability: the innovation paths of social enterprise. Annals of Public and Cooperative Economics, 88, 233-256. https://doi.org/10.1111/apce.12168

Problems of management and economy of companies in the modern conditions. (2017, April). Materials of XIII International Scientific and Practical Conference, $N U$ KhT (196 p.). Brief Report Outlines, Kyiv, Ukraine.

Problems of sustainable development of the economy in the conditions of strengthening globalization processes. (2017, April). Collection of Abstracts of the International Scientific and Practical Conference, TSFEND (100 p.). Poltava.

Report of the International Ministerial Conference of Landlocked and Transit Developing Countries and Donor Countries and International Financial and Development Institutionson Transi Transport Cooperation. (2003, August). Almaty, Kazakhstan. (A/CONF. 202/3), Annex I.

Report of the United Nations Conference on Environment and Development, Riode Janeiro, Vol. I, Resolutions Adopted by the Conference. (1992, June). United Nations publication, Sales No. E.93.I.8 and corrigendum.

Romer, M. (1999). Endogenous technological change. Levine's Working Paper Archive 2135.

Srebotnjak, T., Polzin, C., Giljum, S., Herbert, S., \& Lutter, S. (2010). Establishing environmental sustainability thresholds and indicators: final report. Brussels: Ecologic Institute and SERI.

Sustainability and Performance Assessmentand Benchmarking of Building. (2012). Final report. In T. Häkkinen (Ed.), Espoo 2012. VTT Technology 72 (409 p.)

Thorne, S., \& Raubenheimer, S. (2001). Sustainable development (SD) appraisal of clean development mechanism (CDM) projects - experiences from the South North (SSN) project. Retrieved from http://www.southsouthnorth.org

UNEP. (2012). Green economy: metrics and indicators: Briefing paper. Geneva: UNEP DTIE.

Ürge-Vorsatz, D., Tirado, S., Dubash, N., \& Lecocq, F. (2014). Measuringthe co-benefitsof climate change mitigation. Annual Review of Environment and Resources, 39(1), 549-582. https://doi.org/10.1146/annurev-environ-031312-125456

Vladimir, O. (2017). The objective need to ensure the policy of sustainable development of the country's economy. Socio-Economic Problems and State, 2(17), 13-29.

WRI (World Resources Institute). (2017). CAIT Paris contributions map: explore intended nationally determined contributions (INDCs). Retrieved from http://cait.wri. org/indc/\#/map

Wry, T., \& York, J. (2017). An identity-based approach to social enterprise. Academy of Management Review, 42, 437-460. https://doi.org/10.5465/amr.2013.0506 